\title{
Dioxin scandal triggers food debate in Germany
}

$\mathrm{G}$ ermany, among the top countries in per capita consumption of meat and beer in the world, is not known for healthy eating. The discovery of excessive amounts of the toxic chemical dioxin in eggs, however, has sparked a nationwide debate on the safety of food in the country.

The scandal broke shortly before New Year's Eve, when routine testing of eggs showed dioxin concentrations above those allowed by European Union law. While it first appeared that only a few farms might be involved, it soon became clear that the cause of the dioxin was contaminated animal feed that had been distributed to thousands of farms.

By mid-January, 4700 farms had been closed as a precautionary measure, thousands of chickens killed and hundreds of thousands of eggs destroyed. South Korea, China and other countries suspended imports of pork and poultry from Germany. With the media attention on the issue becoming voluminous, German consumers angrily demanded information on what led to dioxin levels that were in one case 77 times higher than the concentration allowed by law.

Dioxins, or polychlorinated dibenzodioxins, are a group of more than 200 related organic compounds that are produced in the manufacture of organochlorides, pesticides and other chemicals, or used in other processes such as bleaching paper, waste incineration and smelting. They are also created naturally through volcanic eruptions or forest fires, are commonly considered environmental pollutants and are known to bioaccumulate in humans and wildlife.

According to the World Health Organization, they are "highly toxic and can cause reproductive and developmental problems, damage the immune system, interfere with hormones and also cause cancer" (www .who.int/mediacentre/factsheets/fs225 /en/). The degree to which they are metabolized or excreted by animals or humans is believed to depend on the degree to which they are chlorinated,

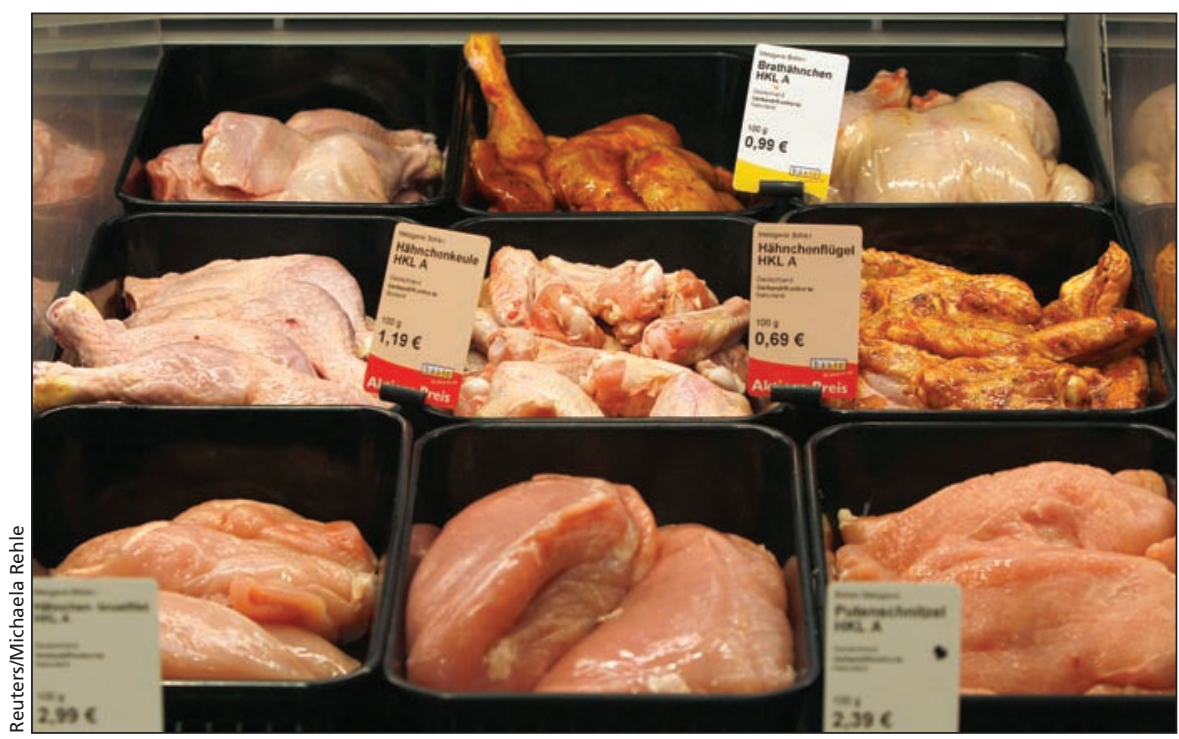

Fresh chicken is pictured in a supermarket meat counter in Germany, where officials issued a health alert after discovering that dioxin-tainted feed had been fed to hens and pigs, contaminating eggs and poultry meat at the affected farms.

so dioxins with few chlorines can be readily oxidized, while highly chlorinated ones can have a half-life anywhere between 7.8 and 132 years (Chemosphere 2009; 48[6]:631-44).

The most toxic dioxin is $2,3,7,8$ tetrachlorodibenzo-p-dioxin, which first became widely known as a component of the controversial herbicide Agent Orange used in the Vietnam War and later made headlines around the world when an accident in a chemical plant in Seveso, Italy, in 1976 led to the release of several kilograms of the substance. Nearly 200 people developed chloracne, an eruption of cysts whose treatment can be very painful, as a result of that incident. The symptoms of the disease could also be seen on Ukrainian president Victor Yushchenko, after it was used to poison him in 2006.

Such history has fed alarm levels within the German populace during the recent food scandal but German officials have consistently stressed that the public has not been in danger.

"There was never any risk for consumers," says Andreas Hensel, president of the Federal Institute for Risk Assessment.
The institute concluded after reviewing the risk posed by dioxincontaminated foods that "even in the theoretical case that somebody had consumed foods with the highest measured dioxin contents for a year, the body burden would only moderately increase. At the end of the year it would have risen after the consumption of a total of 730 eggs with the highest measured dioxin content by 4 picograms to a total of 14 picograms per gram body fat" (www.bfr.bund.de /cd/54049).

Hensel notes that two decades ago, young adults typically had a burden of 30 picograms of dioxins per gram of body fat. "Dioxin is actually a prime example of the reduction of a contaminant in the last decades," he says. "Whether you look at cow milk or breast milk, the amount of dioxin has continually declined over the last 20 years to a fifth of its original value."

The reassurances have done little to assuage public fears about food safety. The scandal has also captured the public's attention and ignited debates about food production, food safety and even, the ethics surrounding the treatment of 
hens that lay eggs and cows that give milk. Television debates about the consequences of industrializing food production have been lively. Roughly 300 German professors have penned a letter calling for an end to large-scale livestock farming. Further fueling the debate is a growing movement toward vegetarianism, prompted in part by the translation into German of American author Jonathan Safran Foer's book, Eating Animals. Polls show every second German is planning to reduce his consumption of meat.

The source of contamination has been identified as the animal feed produced by the company Harles und
Jentzsch. In total, some 3000 tonnes of contaminated fats were used to produce roughly 150000 tonnes of animal feed, almost all of which has already worked its way through the food production chain.

Within a few days of being tagged as the source, the company went bankrupt, so still unanswered is exactly how the dioxins got into the animal feed, although there are indications that mixtures of fatty acids that were intended to be used in the industrial production of lubricants found their way into the animal feed.

"There is a high probability the dioxin originated in materials used for the production of biodiesel," Johannes Remmel, the agriculture minister for the state of North Rhine-Westphalia, told a press conference.

The German government proposed new regulations on Feb. 2 that are aimed at preventing a repeat of the scandal. They will require feed production companies to report all test results to officials (previously that was only necessary if excessive levels of a toxic chemical were found). As well, private laboratories will have to report suspicious results. - Kai Kupferschmidt, Berlin, Germany

CMAJ 2011. DOI:10.1503/cmaj.109-3801 